\title{
Repetition blindness and bilingual memory: Token individuation for translation equivalents
}

\author{
JEANETTE ALTARRIBA and EMILY G, SOLTANO \\ State University of New York, Albany, New York
}

\begin{abstract}
The repetition blindness effect (RB) occurs when individuals are unable to recall a repeated word relative to a nonrepeated word in a sentence or string of words presented in a rapid serial visual presentation task. This effect was explored across languages (English and Spanish) in an attempt to provide evidence for RB at a conceptual level using noncognate translation equivalents (e.g., nephew-sobrino). In the first experiment, $\mathrm{RB}$ was found when a word was repeated in an English sentence but not when the two repetitions were in different languages. In the second experiment, RB was found for identical repetitions in Spanish and in English using word lists. However, the crosslanguage condition produced significant facilitation in recall, suggesting that although conceptual processing had taken place, semantic overlap was not sufficient to produce RB. The results confirm Kanwisher's (1987) token individuation hypothesis in the case of translation equivalents.
\end{abstract}

Repetition blindness (RB) (Kanwisher, 1986, 1987) refers to the inability to recall a repeated word in a rapid serial visual presentation (RSVP) task. For example, for the sentence, "She ate salad and fish even though the fish was raw," readers show poor recall of the second presentation of the word fish relative to recall performance for the following control: "She ate salad and seafood even though the fish was raw." The effect occurs in the repeated case even though the omission of the second word makes the sentence ungrammatical.

$\mathrm{RB}$ is a robust finding and has been reported now by a number of researchers using a variety of different paradigms (e.g., Hochhaus \& Marohn, 1991; Humphreys, Besner, \& Quinlan, 1988; Mozer, 1989). The RB effect has been found when both words differ in case (Kanwisher, 1987; Marohn \& Hochhaus, 1988) and with as many as three intervening words present between the first and the second repetition. Presentation rates of approximately 8 words per second typically yield this effect, and lengthening presentation rate diminishes blindness (Kanwisher, 1987; Park \& Kanwisher, 1994). RB has

This work was supported by a Faculty Research Award granted to the first author from the University at Albany, State University of New York. Portions of these data were presented at the 34th Annual Meeting of the Psychonomic Society, Washington, D.C., November 1993. The authors would like to thank Wendy J. Forsythe for her assistance in the preparation of materials and Janat Parker and Bennett L. Schwartz for the use of their laboratory facilities at Florida International University, Miami. The authors would also like to thank Mercedes A. Altarriba and Mohamed Omar Roumane for verifying the translations of our sentences and words. Daphne Bavelier, Nancy Kanwisher, and Molly Potter provided very helpful discussions throughout the preparation of this manuscript. Thanks are also extended to Kristen Diliberto, Judith Kroll, and Chun Luo for their helpful comments on an earlier draft of this article. Correspondence should be sent to J. Altarriba, Department of Psychology, SS 112, State University of New York, Albany, NY 12222 (e-mail: ja087@ csc.albany.edu). also been reported when the two repetitions appear in different locations on a computer screen (Kanwisher \& Potter, 1989; Luo \& Caramazza, 1996). The effect is not limited to whole words but has also been found with the repetition of individual letters (Bavelier \& Potter, 1992; Bjork \& Murray, 1977; Kanwisher, 1991; Kanwisher \& Potter, 1990; Wolford \& Hollingsworth, 1974), colors (Kanwisher, 1991), pictures/words (Bavelier, 1994), and compressed speech (Miller \& MacKay, 1994).

Kanwisher (1987) explained RB in terms of two dissociable processes: recognition and individuation. In the example presented earlier, both instances of the word fish are of the same type (animal) but must be recognized and encoded as two separate tokens (instances). If the second instance of the word is recognized as a distinct token of that type, then it can be recalled. RB results from a failure to distinguish the repeated word as a distinct token of the type. In this case, the second word is assimilated to the first, and only one token of that word type is reported. Thus, in the example above, the second repetition of the word fish is not recognized as a distinct event or token in the first sentence and is not recalled. Only the first instance of a word is represented in episodic memory. Although substantial evidence has been reported supporting this interpretation (however, see Fagot \& Pashler, 1995, and Whittlesea, Dorken, \& Podrouzek, 1995, for alternative explanations), the exact nature of this effect is still a mystery.

Kanwisher and Potter (1990) examined the levels of processing that influence RB. They argued that the effect occurs at a level prior to a conceptual level in which orthographic or lexical codes are accessed. RB was found in cases in which homonyms were used (e.g., [the] rose vs. [she] rose), cases in which homographs were used (e.g., [the] wound vs. [she] wound), and cases in which words and compounds were used (e.g., dog and hotdog). In their experiments, the words were embedded in sen- 
tences using RSVP at a rate of $117 \mathrm{msec}$ per word. The participant's task was to recall the sentence aloud as soon as possible when the sentence ended. Words that had partial orthographic overlap (e.g., cap and cape) also showed the effect. In fact, other researchers have reported that repetition blindness occurs between orthographic neighbors differing only by a single letter, although the magnitude of the effect is not as great as that reported for identical items (Bavelier, Prasada, \& Segui, 1994).

Kanwisher and Potter (1990) also discussed several situations that failed to produce a repetition blindness effect. For example, no evidence of RB at a conceptual level was found in cases in which the repetitions were synonyms (e.g., autumn-fall, soil-dirt). Recall in the synonym condition was equal to the unrepeated or control condition. These results suggest that, in visual tasks, RB is primarily the result of orthographic overlap or orthographic identity across tokens of the same type and is not present at the level of meaning.

Other evidence suggests that phonological codes are also involved in repetition blindness. In fact, Bavelier and Potter (1992) suggested that visual similarity is not necessary to produce RB. They reported repetition blindness in recall for homophonic pairs (e.g., won-one) and for pairs of numerals that appeared in different formats (e.g., 9-nine) using a three-word list presentation at a rate of $100 \mathrm{msec}$ per item. ${ }^{1}$ In both cases, the phonological overlap between repetitions was identical with slight or no overlap in visual features. It appears that phonological similarity is sufficient to produce the repetition blindness effect. Similar results were reported by Bavelier et al. (1994) with words that share a phonological overlap but are visually distinct (e.g., crude-brood, juice-loose). Bavelier and Potter (1992) suggested that the repetition blindness effect found for phonologically similar words results from the inability to reselect a phonological representation that has recently been used for the registration of information in short-term memory. Specific attributes - in this case, phonological onesrelated to a type are registered when the first token is instantiated, and subsequent attempts to register the same attributes may be useless for some interval of time. Therefore, a new token cannot be readily established in a short period of time. Bavelier (1994), however, suggested an alternative explanation. She reported RB for pictures and words (i.e., a picture of a pumpkin and the word pumpkin) for which phonological codes were identical but visual codes were distinct. In this study, target words and pictures appeared in sentences that were presented one word at a time using RSVP at a rate of $83 \mathrm{msec}$ per item. According to Bavelier, this effect stems from the loss of an open token that was created when the second target was processed or a failure to stabilize that token, rather than the inability to identify the second item as a separate token. More will be said regarding this hypothesis in the General Discussion section.

Although RB has been shown in cases where the two target words are visually identical or phonologically similar, the effect has not been shown for words with simi- lar meanings (e.g., couch-couch shows blindness but sofa-couch does not; Kanwisher \& Potter, 1990). ${ }^{2}$ It can be argued, however, that in cases in which the two target items differ only in visual similarity (e.g., 8-eight, or the picture of a cat and the word cat), that meaning might also play a role in the repetition blindness effect (Bavelier, 1994; Bavelier \& Potter, 1992). Perhaps a stronger test of the role of meaning in RB is to test for this effect in cases in which there is no visual or phonological overlap between words that share an identical meaning. A natural candidate for this test is the use of noncognate translation equivalents (e.g., nephew and its Spanish translation sobrino).

The use of within-language synonyms may appear useful in examining RB at a conceptual level. However, previous research suggests that the semantic relationship across synonyms may not be as strong as that between identical repetitions. For example, Dannenbring and Briand (1982) used a lexical decision task to investigate priming for repetitions (e.g., ocean-ocean) relative to words that were closely related in meaning (e.g., seaocean). Word pairs were presented with lags of $0,1,5$, or 16 intervening items. Strong repetition priming effects were observed at every lag interval, but priming for related words was small and occurred only at Lag 0 . Priming for words that are semantically related or for synonyms may be short lived. Other researchers have also reported little or no priming effects with words that are indirectly related (Mandler, Graf, \& Kraft, 1986; Napps, 1989; Weldon, 1991). Roediger and Challis (1992) examined conceptual priming for word-fragment completions for synonyms, associates, category members, visually similar words, repetitions, and unrelated words. Paricipants were instructed to read and study a long list of words that were related to a target completion on one of the above relational categories. Participants were then presented with word fragments and were asked to complete them. Twenty seconds were given to complete each fragment, and no mention was made of the previous study phase. Significant priming effects were found in the direct (repetition) condition, but none of the other indirect conditions produced significant results. Although it can be argued that primed word-fragment completion tasks may not depend on conceptual representations (Blaxton, 1989; Roediger, Srinivas, \& Weldon, 1989; Roediger, Weldon, \& Challis, 1989), a second experiment conducted by Roediger and Challis involving free recall again revealed an advantage for repeated items. Recall for target items followed by exact repetitions was superior to recall of target items followed by synonyms or associates.

In contrast to the findings regarding priming for synonyms, ample evidence exists of strong priming effects in lexical decision for semantically related words across languages (Chen \& Ng, 1989; Dalrymple-Alford, 1982; Frenck \& Pynte, 1987; Keatley \& de Gelder, 1992; Kirsner, Smith, Lockhart, King, \& Jain, 1984; Schwanenflugel \& Rey, 1986; Tzelgov \& Eben-Ezra, 1992). Specifically, studies of cross-language priming for translations indicate that a word and its noncognate translation may 
share a common conceptual representation (Altarriba, 1992; Chen \& Ng, 1989; de Groot \& Nas, 1991, Experiment 3; Jin (1990); Keatley \& de Gelder, 1992, Experiment 4). Altarriba (1992), for example, presented fluent Spanish-English bilinguals with pairs of translations (e.g., sweet-dulce) for lexical decision. A sequential presentation procedure was used and the stimulus onset asynchrony (SOA) was either 200 or $1,000 \mathrm{msec}$. Both relatedness proportion and nonword ratio were low (.33) to minimize the use of response strategies. It has been found that an increase in relatedness proportion yields an increase in the magnitude of the priming effect, as participants respond on the basis of semantic relatedness rather than lexicality (de Groot, 1984; Neely, Keefe, \& Ross, 1989). Significant priming effects were shown at the long SOA in both directions (i.e., English-Spanish and Spanish-English) and at the short SOA for EnglishSpanish pairs. Thus, it has been established that translation equivalents are closely related in semantic memory, and priming for these words has sometimes been found to be equal in magnitude to within-language, repetition priming effects (see, e.g., Tzelgov \& Eben-Ezra, 1992, and Keatley \& de Gelder, 1992, Experiment 1). Moreover, Paivio, Clark, and Lambert (1988) reported that semantic repetition effects in free recall were stronger for translations in French and English than for within-language synonyms.

The present cross-language experiments were designed to examine whether conceptual overlap is sufficient to produce repetition blindness in sentences and word lists. Although repetition blindness for noncognate translations has not been examined previously using word lists, MacKay and Miller (1994) investigated this effect using mixed-language, English-Spanish sentences. They noted that the synonym pairs that were embedded in sentences used by Kanwisher and Potter (1990) may not have shared the same referent and, therefore, may not have been the ideal stimuli to use. For example, read Sentences 1 and 2 below.

1. The pupils worked with students who could help them.

2. That taxi passed our $c a b$ very quickly.

The synonym pairs used here refer to different items or tokens rather than the same item. MacKay and Miller suggested that this might have worked against finding RB for synonyms in Kanwisher and Potter's study. Clearly, within-language synonyms may also have different connotations and slightly different meanings, as mentioned earlier, whereas translation equivalents for concrete nouns that are commonly used may share a complete overlap of semantic features (see de Groot, 1993, for a discussion of the representation of concrete vs. abstract words and their translations).

MacKay and Miller (1994) asked Spanish-English bilingual participants to recall sentences that had been presented using RSVP. The sentences were mixed in English and Spanish with different numbers of words in either language across sentences. The two target items in each sentence were within-language repetitions (e.g., horses-horses, caballos-caballos), translations (e.g., horses-caballos, caballos-horses), or unrelated (e.g., sheep-horses, oveja-caballos, sheep-caballos, ovejashorses). Sentences were presented at a rate of either 70 or $90 \mathrm{msec}$ per word, and presentation rate was varied within subjects across the various experimental conditions. There were at least one or two intervening words between the presentation of the two target words. In cases in which the translations of the sentences required more words in Spanish than in English, more than one word was shown in a given frame on the computer screen. An attempt was made to equate number of frames across the different sentence conditions, rather than number of words.

Repetition blindness was found within language for the identical repetitions as well as across language for the translations. Participants were less likely to report the second repetition of a word following its translation than following an unrelated, cross-language word. In fact, the magnitude of blindness reported was equal both within and between languages. However, there are several ways in which their approach differed from that typically reported in the literature that should be mentioned here. First, in other studies of RB, the presentation rate remained constant throughout the duration of the experiment and was typically no less than $80-100$ msec per word when using sentences (Kanwisher, 1987; Kanwisher \& Potter, 1990). Second, whereas participants in other published studies typically produced high recall rates (see, e.g., Kanwisher, 1987), overall recall in their study for the second target item averaged $39 \%$, as estimated from their results. Third, they varied the amount of information that is processed during any one screen from one to three words rather than presenting a single word on the screen at a time, as in most studies.

Although the above differences may not account for the repetition blindness that was reported by MacKay and Miller (1994), other issues regarding the nature of the materials used and the language background of their participants may have contributed to the effect. First, several of the examples that have been reported in their published paper and previous manuscript that detailed the materials used in the present study were ungrammatical (MacKay \& Miller, 1992). Examine the example in Sentence 3 below.

3. They saw horses, but caballos were prohibitir to enter.

(MacKay \& Miller, 1994, p. 52)

In this sentence, the word prohibitir is not an acceptable word in either Spanish or English. The correct Spanish translation should be the past participle of the verb prohibit or prohibido. Sentence 4 below is another example.

4. They saw oveja, but caballos were prohibitir to enter.

(MacKay \& Miller, 1994, p. 53)

Besides the incorrect form of the verb prohibit, the Spanish word for sheep, oveja, should be used in the plural 
form, ovejas. Unlike the English version of this word, in Spanish this word is made plural by the addition of a final "s." A final example can be seen in Sentence 5.

5 . We requested water cuando agua había. (MacKay \& Miller, 1992, p. 8)

In an attempt to translate this sentence word for word from the English sentence, "We requested water when water was available," the final two words of the sentence were correctly translated into the word habia. However, it is standard to place the verb before the noun as in habia agua rather than the way they presented it in their sentence. Therefore, although not ungrammatical, this sentence would not be an example of a commonly used phrase.

In relation to the repetition blindness effect, the problems with grammaticality of the materials might have increased the level of difficulty of processing these mixedlanguage sentences. One of the consequences of this problem might have been the low percentage of overall recall as noted above. Another consequence might have been an increase in the difficulty in processing the second target word in certain conditions due to the inclusion of misspelled words. Thus, part of the RB effect may have been due to interference from an attempt at processing other nonlexical items.

Another issue to consider relates to the participants' relative level of fluency in English and in Spanish. It appears that not all of the participants included in MacKay and Miller (1994) were equally fluent in both languages or shared a similar language history. Only $73 \%$ listed Spanish as their first language, 23\% listed English, and $4 \%$ represented other language groups. Participants also rated themselves as being more fluent in English than in Spanish. This might account for the overall reduction in recall performance noted earlier. The sentences included several code switches that might have negatively influenced recall performance for the entire sentence. Macnamara and Kushnir (1971), for example, found that FrenchEnglish bilinguals required extra time to read passages that were mixed as opposed to unilingual passages. Successive code switching takes up processing time and perhaps memory capacity and may inhibit full recall of a mixed-language sentence. Also, given that the crosslanguage results included both the results when the first target was in English and the second target was in Spanish and the reverse, it is not possible to partial out the effects of language direction. Bavelier (1994) and Park and Kanwisher (1994) have noted that when the second item is made salient, overall repetition blindness is reduced because the second item can be easily individuated as a separate token. In MacKay and Miller, repetition blindness might have occurred when the first item appeared in Spanish and the second item in English because the participants were better skilled in English. Therefore, the second item was not particularly salient. In the EnglishSpanish case, the Spanish item might have been more salient, and the RB effect might have been minimal or might not have occurred at all.

In summary, it is possible that any of these concerns influenced the reported repetition blindness effect across languages, and it is difficult to conclude that semantic or conceptual overlap is sufficient to produce repetition blindness on the basis of this single set of results. The purpose of the present set of experiments was to investigate repetition blindness across languages in sentences and short word lists under well-controlled conditions. Experiment $1 \mathrm{~A}$ was used as a pilot study to test materials and procedures. English monolingual participants recalled English sentences presented using RSVP in which target words were either repeated or unrepeated. In Experiment 1B, fluent Spanish-English bilinguals recalled the same sentences as those in Experiment 1A; however, the language of the repeated word was switched. In Experiment 2 , the same group of bilingual speakers was asked to recall a list of three words interspersed among rows of symbols that were presented using RSVP. The first and third words were either within-language repetitions or noncognate translations. If repetition blindness occurs for code-switched words that are related only in meaning, then RB may be attributed to a conceptual overlap.

\section{EXPERIMENT 1A}

Monolingual English-speaking students were presented with sentences using RSVP in which a target word appeared in either a repeated or an unrepeated condition. The sentences were constructed such that they could be easily translated into Spanish for Experiment 1B while preserving grammaticality. Our aim was to replicate the repetition blindness effect within English using our stimuli and methods.

\section{Method}

Participants. Thirty-four native English speakers from the University at Albany, State University of New York, participated for partial course credit.

Materials. There were 18 critical sentences. Sixteen of the sentences were adapted from Kanwisher (1987) and Bavelier and Potter (1992) and modified such that they could be easily translated into Spanish. The remaining 2 sentences were generated by the experimenters. All of the materials were independently verified for accuracy in Spanish by two fluent Spanish-English bilinguals currently living in a bilingual community in Miami, FL. In addition, translations were compared against those provided by Smith, Davies, and Hall (1989) and were chosen such that they were the most commonly used translations in the bilingual population to be tested in subsequent studies (i.e., students in Miami).

The sentences ranged in length from 8 to 14 words, with an average length of 10.6 words. There were one to three intervening words between the two critical target items. The target words were never in the first or last position in the sentences. In most cases, the omission of the second target word (R2) would render the sentence ungrammatical. ${ }^{3}$

There were two versions of each sentence. In one version, the two critical target items were exact repetitions (repeated condition). In the second version, the first target word (R1) was replaced 
by another word that maintained the grammaticality of the sentence (unrepeated or control condition). The 18 sentences and their corresponding controls are included in Appendix A. (Although the target words appear highlighted [italicized] in the appendices, they were not highlighted in the actual sentences.)

The repeated and unrepeated sentences were counterbalanced across two stimulus lists such that a given sentence appeared in only one condition within a list. The sentences were randomly ordered on each list with the constraint that no more than 2 sentences in a given condition appeared on consecutive trials. Each participant saw only one list on which there were 9 repeated sentences and 9 unrepeated sentences.

Procedure. The experiment began with four practice trials, 2 sentences in the repeated condition and 2 sentences in the unrepeated, control condition, in order to acquaint the participant with the task. The same list of practice sentences was shown to each participant, and none of the practice sentences appeared on the experimental lists. Experiment $1 \mathrm{~A}$ was run on an IBM PC computer with white lettering on a black background, and Experiments $1 \mathrm{~B}$ and 2 were run on similar computers using amber lettering on a black background. All of the words were presented in lowercase with the exception of the first word in each sentence, which was presented in uppercase.

Each trial began with a row of 13 plus $(+)$ signs displayed for $2,000 \mathrm{msec}$ in the center of the computer screen. A sentence was then presented one word at a time in the center of the screen (RSVP) at a rate of $117 \mathrm{msec}$ per word. Immediately after the presentation of the final word, the participants were instructed to recall aloud all of the words they had seen in the order in which they had been presented. The participants were also told that some of the sentences might not be grammatically correct and that they should not add words to make sense of the sentence they had seen. The participants pressed the " $\mathrm{H}$ " key on the keyboard when they were ready to proceed to the next sentence. Responses were recorded using a cassette player, and the experimenter remained in the room with the participant to transcribe the responses. An experimental session lasted approximately $15 \mathrm{~min}$.

\section{Results and Discussion}

Overall performance on sentence recall was high and averaged $80 \%$. This result was computed by adding together the total number of words recalled and dividing by the total number of words presented for each subject. An average was then computed across subjects. The percentages of trials on which R 1 (the first target word) and $\mathrm{R} 2$ (the second target word) were correctly recalled in the repeated and unrepeated conditions are shown in Table 1.

In a few cases in which it was difficult to determine whether the target word recalled was R1 or R2, it was scored conservatively as R2. Analyses of variance (ANOVAs) were used in this and subsequent experiments with participants as the random variable $\left(F_{1}\right)$ as well as with items as the random variable $\left(F_{2}\right)$.

The primary focus here was recall performance for R2 in the repeated and unrepeated conditions, since this experiment was not designed to evaluate recall performance on R I given that different words were used for R 1 in the repeated and unrepeated conditions. There was a main effect of repeatedness for $\mathrm{R} 2\left[F_{1}(1,33)=12.68, M S_{\mathrm{e}}=\right.$ $\left.0.03, p<.01 ; F_{2}(1,17)=5.74, M S_{\mathrm{e}}=0.03, p<.05\right]$. The participants recalled $\mathrm{R} 2$ in $80 \%$ of the unrepeated trials and in $66 \%$ of the repeated trials. Thus, a strong RB effect was found for recall of R2.
Table 1

Percentage of Trials on Which R1 and R2 Were Recalled in English Sentences (Experiment 1A) and in Mixed-Language Sentences (Experiment 1B)

\begin{tabular}{ccc}
\hline & \multicolumn{2}{c}{ Condition } \\
\cline { 2 - 3 } Target & Repeated & Unrepeated $^{*}$ \\
\hline R1 & Experiment 1A & 91 \\
R2 & 69 & 80 \\
& 66 & \\
R1 & Experiment 1B & 65 \\
R2 & 75 & 64 \\
\hline
\end{tabular}

*For R1 target words in this condition, the recall of the unrelated control word replacing $\mathrm{R} 1$ was scored.

The finding of a repetition blindness effect within the English sentences used here indicates that these materials and the procedures followed can be used successfully within this paradigm. The participants selectively omitted the second presentation of a word that had been repeated earlier in the sentence. In Experiment 1B, the target words appeared in two different languages, English and Spanish, in an attempt to provide evidence of RB across languages.

\section{EXPERIMENT 1B}

The purpose of this experiment was to directly test whether repetition blindness occurs at a semantic level by asking fluent, Spanish-English bilingual participants to recall sentences that contained noncognate translations. If conceptual overlap is sufficient to produce RB, then participants should show difficulty in recalling a target word following presentation of its translation relative to an unrelated code-switched word.

\section{Method}

Participants. Fifty-two Spanish-English bilingual speakers from the Florida International University community, Miami, participated in this experiment. The participants received extra credit toward their final grade in a psychology course or monetary compensation in the amount of $\$ 5.00$. A language background questionnaire was administered to ensure that the participants were in fact Spanish-English bilinguals. Table 2 includes data on the participants' language histories in Experiments $1 \mathrm{~B}$ and 2.

The data presented in Table 2 indicate that the participants rated themselves as highly fluent readers and speakers of both English and Spanish. The experiment was conducted in Miami, since this city provides an environment in which both English and Spanish

Table 2

Responses to Language History Questionnaires for Participants in Experiment $1 B$ and Experiment 2

\begin{tabular}{lcc} 
& Experiment 1B & Experiment 2 \\
\hline Mean age in years & 24.8 & 24.5 \\
Mean years in U.S. & 13.9 & 13.8 \\
Mean years in U.S. schools & 10.8 & 10.9 \\
Mean self-ratings on ability to & & \\
$\quad$ (10-point scale): & & \\
$\quad$ read/write English & 9.3 & 9.3 \\
$\quad$ read/write Spanish & 9.1 & 9.1 \\
\hline
\end{tabular}


are widely used on a daily basis and, within this city, there are many opportunities for students to read printed material in both languages.

Materials. The sentences in Experiment $1 \mathrm{~A}$ were translated into Spanish, and sentences were presented such that the first half was in one language and the second half was in the other language. The language switch always occurred between R1 and R2. Four versions of each sentence were created: (1) Spanish-English, repeated, where the target words were exact translations; (2) SpanishEnglish, unrepeated, where the target words were not translations (although they were in different languages); (3) English-Spanish, repeated; and (4) English-Spanish, unrepeated. Language condition (Spanish-English or English-Spanish) was manipulated between subjects such that one group of participants saw SpanishEnglish sentences and the second group saw English-Spanish sentences.

Four stimulus lists were created, two in each of the language conditions noted above. The repeated and unrepeated sentences were counterbalanced across stimulus lists such that a given sentence appeared in only one condition within a list. The sentences were randomly ordered on each list with the constraint that no more than 2 sentences in a given condition appeared on consecutive trials. Each participant saw only one list on which there were 9 repeated sentences and 9 unrepeated sentences. The sentences used and their corresponding controls are included in Appendix B.

Procedure. The procedures were the same as those in Experiment $1 \mathrm{~A}$ except that the rate of presentation was $133 \mathrm{msec}$ per word. In addition, the participants filled out a language-background questionnaire at the end of the session.

\section{Results and Discussion}

Overall performance on sentence recall averaged $60 \%$ and was computed as in Experiment $1 \mathrm{~A}$. The percentages of trials on which R1 and R2 were correctly recalled in the repeated and unrepeated conditions are shown in Table 1. The data were collapsed across language condition, since results were similar in both language directions, and there was no main effect of language $(p>.05)$.

As in Experiment $1 \mathrm{~A}$, the main focus here was recall performance for $\mathrm{R} 2$ in the repeated and unrepeated conditions. There was no main effect of repeatedness for $\mathrm{R} 2$ $(F \mathrm{~s}<1)$. The participants' recall performance was similar for R2 in the repeated and unrepeated conditions. In short, there was no evidence of repetition blindness across languages for mixed-language sentences. The participants recognized each instance of a word and its translation equivalent as separate tokens. Thus, it appears that fluent bilinguals can token individuate noncognate translations, leading to the recall of both target words in the repeated condition.

These results fail to support those of MacKay and Miller (1994) and indicate that conceptual relatedness alone is not sufficient to produce an RB effect. One possible explanation for the discrepancy between the results of the present experiment and those of MacKay and Miller relates to the fact that the language switching within the sentences occurred in different locations. In the present experiment, the switching occurred in the middle of each sentence, whereas, in MacKay and Miller's study, a language switch occurred several times in each sentence. Participants in their study might have been bi- ased toward focusing their attention on the meanings of words rather than their lexical form. In the present experiment, the second repetition of the word might have been particularly salient, given that it always appeared in a different language than the first repetition. The saliency of R2 might have reduced the possibility of an RB effect (see, e.g., Bavelier, 1994). ${ }^{4}$ Given that it was possible that the participants were biased toward processing the distinct forms of each of the translation equivalents and not their meaning, it follows that repetition effects would not occur for these words. In addition, caution must be used when interpreting these results, since overall performance on sentence recall $(60 \%)$ indicates that perhaps this task was too difficult. The participants might have suffered from the increase in memory load provided by the language switch and the requirement to report all items in order, in the correct language. The problem here is not one of presentation rate - pilot studies revealed that longer presentation rates produced ceiling effects, whereas shorter presentation rates using these materials produced extremely low overall recall. In the present case, memory load might have influenced the recall of both $\mathrm{R} 1$ and $\mathrm{R} 2$ in the repeated and the unrepeated condition. ${ }^{5}$

To remedy the above situation, short word lists were used in Experiment 2. Participants were shown two- or three-word lists using RSVP and were asked to perform serial recall of the words. Target words were either within language (English or Spanish) or across language (Spanish-English or English-Spanish). The advantages of using word lists over sentences is that overall memory load is decreased, thus facilitating recall, and issues regarding sentence grammar and syntax are irrelevant.

\section{EXPERIMENT 2}

To our knowledge, this is the first experiment to explore cross-language RB for noncognate translations using word lists. The method used was similar to that of Bavelier and Potter (1992). The question in Experiment 2 is the same as in Experiment 1B: Is conceptual overlap sufficient to produce a repetition blindness effect across languages?

\section{Method}

Participants. Forty-eight students from the same sample as that in Experiment IB participated for either course credit or $\$ 5.00$.

Materials. Seventy-two experimental trials were used along with 18 filler trials. Each trial consisted of a string of seven items presented using RSVP. Three of the items were words and four of the items were symbol sets. A typical arrangement of items consisted of a string of percentage (\%) signs followed by another string of symbols, then the first target word (R1) followed by an intervening word, and then the other target word (R2). These items were then followed by another string of symbols and a row of percentage signs. The target items always appeared in the same serial position. Specifically, $\mathrm{R} 1$ always occurred in the third position, and R2 always occurred in the fifth position. A sample trial can be seen in Figure 1. 


\section{8?8\%}

$\boldsymbol{t} t \boldsymbol{t} \boldsymbol{k} \boldsymbol{k}$

nephew

(R1)

\section{duck (intervening word)}

nephew

(R2)

\section{?????}

\section{8\%}

Figure 1. Sample trial for Experiment 2.

R1 and R2 consisted of English words and their Spanish translations chosen from Kučera and Francis (1967) and Smith et al. (1989). The critical words used in Experiment 2 can be found in Appendix $C$. Language of $R 1$ and $R 2$ was manipulated to create the following four conditions: English-English, Spanish-Spanish, Spanish-English, and English-Spanish. The first language refers to the language of $R 1$, and the second language refers to the language of R2 on a given trial. Repeatedness was also manipulated such that a pair of words appeared in both the repeated and the unrepeated conditions. $\mathrm{Rl}$ in the unrepeated condition was always matched on a pair-by-pair basis for length and frequency in English (Kučera \& Francis, 1967) and was semantically unrelated to $\mathrm{R} 2$. Finally, the language of the intervening word (the word between R1 and R2) was manipulated in the cross-language conditions (Spanish-English and English-Spanish) such that, on half of the trials, the intervening word was in Spanish and, on the other half of the trials, the intervening word was in English. On the within-language trials (Spanish-Spanish and English-English), the intervening word matched the language of R1 and R2.

The above variables were combined to create 12 experimental conditions. Six items in each condition appeared on every experimental list. Conditions were counterbalanced across 12 lists such that every item appeared in every condition, and each item in each list was unique. Items were presented randomly on each list, and a given item appeared in the same serial position across lists. Each participant saw a single list. A typical filler trial consisted of four symbols and two words. Words in the filler trials were always unrelated and were either in the same language or in different languages. Fillers were included so that the participants would not feel compelled to respond with three words on each trial.

Procedure. The participants began with 16 practice trials to acquaint them with the task. Each trial began with a row of 12 "@” signs displayed in the center of the computer monitor for $2,000 \mathrm{msec}$ The items (symbols and words) on each trial were displayed sequentially in the center of the screen (RSVP) at a rate of $125 \mathrm{msec}$ per item. The participants were instructed to read the words on the computer monitor and ignore the symbols. After presentation of the last symbol string, the participants were instructed to recall the words they had seen in the order in which they had appeared. They were cautioned to repeat each word in the correct language and not to translate any words. Also, they were told that a word might occur twice. The participants pressed the " $\mathrm{H}$ " key on the keyboard when they were ready to proceed to the next trial. Responses were recorded by a cassette player, and, as in Experiment $1 \mathrm{~B}$, the experimenter remained in the room with the participant to transcribe the responses. The participants also completed a language-background questionnaire (see Table 2): Each session lasted approximately $40 \mathrm{~min}$.

\section{Results and Discussion}

ANOVAs on the percentage of trials in which both R1 and $\mathrm{R} 2$ were recalled in the different conditions were conducted. Unlike in Experiments $1 \mathrm{~A}$ and $1 \mathrm{~B}$, it was often difficult to decide whether $\mathrm{R} 1$ was missing or had changed serial position. Therefore, the recall of both $\mathrm{RI}$ and R2 seemed to be a clearer indicator of the RB effect in Experiment 2 (see, e.g., Bavelier, 1994, and Bavelier \& Potter, 1992). Trials with identical repetitions were analyzed separately from those with translations, because the primary interest was in examining the cases in which the overlap was strictly semantic (i.e., the translations). The identical items overlapped semantically, but the amount of orthographic and phonological overlap between these items was higher than between translations.

Overall performance on recall for word lists was $71 \%$. This result was computed by adding together the total number of words recalled and dividing by the total number of words presented for each subject. An average was then computed across subjects. The percentages of trials on which both R1 (the first target word) and R2 (the second target word) were both correctly recalled in the repeated and unrepeated conditions within language are shown in Table 3.

For the within-language conditions, an ANOVA was carried out with repeatedness (repeated or unrepeated) and language of R1 and R2 (English or Spanish) as withinsubjects variables. There was a main effect of repeatedness $\left[F_{1}(1,47)=45.75, M S_{\mathrm{e}}=0.09, p<.001 ; F_{2}(1,71)=\right.$ $\left.95.03, M S_{\mathrm{e}}=0.06, p<.001\right]$. Overall, recall performance was higher for unrepeated items $(62 \%)$ than for repeated items $(32 \%)$. However, there was no main effect of language $(p s>.05)$. The interaction between repeatedness and language was significant $\left[F_{1}(1,47)=9.06, M S_{\mathrm{e}}=\right.$ $\left.0.05, p<.01 ; F_{2}(1,71)=7.80, M S_{\mathrm{e}}=0.07, p<.01\right]$. Planned comparisons indicated that there was a significant RB effect in English $\left[F_{1}(1,47)=72.44, M S_{\mathrm{e}}=3.76\right.$, $\left.p<.001 ; F_{2}(1,71)=71.6, M S_{\mathrm{e}}=4.8, p<.001\right]$ and a significant RB effect in Spanish $\left[F_{1}(1,47)=18.11, M S_{\mathrm{e}}=\right.$ $\left.0.94, p<.001 ; F_{2}(1,71)=20.37, M S_{\mathrm{e}}=1.36, p<.001\right]$.

Table 3

Percentage of Trials in Which R1 and R2 Were Both Recalled in the Within-Language and Between-Language Conditions of Experiment 2

\begin{tabular}{lcc}
\hline & \multicolumn{2}{c}{ Language of Intervening Word } \\
\cline { 3 - 3 } Repeatedness & English & Spanish \\
\cline { 3 - 3 } Repeated & Within-Language Condition & \\
Unrepeated & 29 & 35 \\
& 69 & 55 \\
Repeated & Between-Language Condition & \\
Unrepeated & 79 & 74 \\
\hline
\end{tabular}


The participants recalled $40 \%$ more items in the unrepeated condition than in the repeated condition for English items. For Spanish items, an average of $20 \%$ more was recalled in the unrepeated condition than in the repeated condition. Thus, a repetition blindness effect was found within language in both Spanish and English, and the magnitude of the effect was larger for identical repetitions in English. These findings replicate those reported by Bavelier and Potter (1992) and others for English repetitions and confirm the finding that orthographic and phonological overlap are sufficient for RB to occur.

For the cross-language conditions, an ANOVA was carried out with repeatedness (repeated or unrepeated), language order of R1 and R2 (English-Spanish or SpanishEnglish), and language of intervening item (English or Spanish) as within-subjects variables. Since there was no main effect of language order $(F<1)$, the data for the repeated and unrepeated conditions were collapsed across this variable and are presented in Table 3 . There was a main effect of repeatedness $\left[F_{1}(1,47)=36.67, M S_{\mathrm{e}}=\right.$ $\left.0.04, p<.001 ; F_{2}(1,71)=49.34, M S_{\mathrm{e}}=0.03, p<.001\right]$. Surprisingly, repeated items were recalled better $(77 \%)$ than unrepeated items $(63 \%)$. There was also a main effect of language of intervening item $\left[F_{1}(1,47)=14.38\right.$, $M S_{\mathrm{e}}=0.02, p<.001 ; F_{2}(1,71)=11.56, M S_{\mathrm{e}}=0.03, p<$ $.01]$. Recall performance was higher when the language of the intervening items was English ( $74 \%$ vs. $66 \%$ ). However, there was no interaction between repeatedness and language of intervening item $(F \mathbf{s}<1)$.

Planned comparisons indicated that the advantage in recall for repeated items was significant when the intervening items were in English $\left[F_{1}(1,47)=13.42, M S_{\mathrm{e}}=\right.$ $\left.0.235, p<.001 ; F_{2}(1,71)=16.04, M S_{\mathrm{e}}=0.547, p<.001\right]$ and in Spanish $\left[F_{1}(1,47)=29.16, M S_{\mathrm{e}}=0.51, p<.001\right.$; $\left.F_{2}(1,71)=11.56, M S_{\mathrm{e}}=0.03, p<.01\right]$. In other words, rather than repetition blindness, we found significant repetition priming effects across languages. Repetition priming effects across languages have been reported previously in free recall tasks using a variety of methods, and the general finding is that cross-language repetition increases recall as well as learning rate of the second presentation of a word (Glanzer \& Duarte, 1971; Kolers, 1966; Kolers \& Gonzalez, 1980; Lambert, Ignatow, \& Krauthamer, 1968; Liepmann \& Saegert, 1974; Nott \& Lambert, 1968; Paivio et al., 1988; Rose \& Carroll, 1974; Tulving \& Colotla, 1970). For example, Kolers and Gonzalez (1980) presented participants with a set of 45 Spanish and English words. Repetitions were in the same language or different languages, and items were presented from one to three times. Recall increased with the number of presentations, and effects were the same within and across languages. It is interesting to note that the cross-language repetition priming effects found in the present experiment were unexpected given that the method used here has been used previously by Bavelier and Potter (1992) to demonstrate repetition blindness.
The facilitation found in the present experiment for translation equivalents indicates that these items were processed at a conceptual level. However, semantic relatedness actually improved recall rather than producing a repetition blindness effect. These results are interesting given the finding of repetition blindness effects in the within-language conditions, within the same experiment. Thus, a dissociation occurred in which repetitions across languages facilitated recall, whereas identical repetitions within languages produced blindness. Kanwisher's (1987) token individuation hypothesis will be discussed in the next section, because it provides a viable explanation for these results.

\section{GENERAL DISCUSSION}

The results of Experiments 1 and 2 suggest that semantic similarity alone is not sufficient to produce a repetition blindness effect. In Experiment 1, repetition blindness emerged for words embedded in English sentences but not in the mixed-language case. This finding contradicts earlier results reported by MacKay and Miller (1994) using mixed-language sentences. The goal of Experiment 2 was to investigate cross-language RB using short word lists, a task that would minimize the memory demands of Experiment 1 . The finding of RB within-languages and facilitation across languages indicated that although the cross-language words were being processed at a conceptual level, semantic overlap actually aided recall for noncognate translations rather than producing blindness.

Previous studies using pictures and words have indicated that semantic/lexical similarity can play a role in RB (Bavelier, 1994; Yin, Wojciulik, \& Kanwisher, 1993). However, both pictures and words may share a larger number of similar codes (phonological, lexical, semantic, articulatory, etc.) than two different language words. Bavelier (1994) suggested that RB can be found between two visually dissimilar items if similar codes are used to stabilize the tokens. In this view, two separate tokens are opened, one for R 1 and one for R2, and then a stabilization process occurs in short-term memory. The stability of a token is a function of the number and strength of the codes that are registered into it. Once the codes for $\mathrm{R} 1$ have been registered, subsequent reactivation of those codes may not be interpreted as belonging to a new object (R2) but rather considered part of the first token (R1). That is, a given code cannot be registered into more than one token in a brief period of time. Consequently, there is a failure to stabilize R2, and R2 is lost. In the cross-language case, it appears that a word and its noncognate translation do not share a sufficient number of codes to pose problems for the stabilization process. In other words, both words can be opened as separate, stable tokens and can be successfully recalled without any losses. Biasing readers toward registering similar codes in tokens by varying task requirements has been shown to produce repetition blindness for monolingual speakers 
using pictures and words (Bavelier, 1994). Thus, the stability of new tokens may be influenced not only by the encoding of their features but also by task demands.

\section{Support for Token Individuation}

Kanwisher's (1987) token individuation hypothesis is similar to Bavelier's (1994) explanation for repetition blindness. The failure to find cross-language RB indicates that a word and its noncognate translation are sufficiently different in terms of features or characteristics so as to permit the creation of distinct tokens. With short word lists, memory for both tokens was actually facilitated in an RSVP paradigm. ${ }^{6}$ In fact, several participants in Experiment 2 anecdotally reported at the end of the testing session that the words that were repeated in two languages were easier to recall. It appears that the first item acted as a "prime" and that the saliency of both items was increased when both words were exact translations. The difference in language codes between R1 and R2 might have provided the saliency necessary to fully instantiate both tokens as separate, individual items. Bavelier (1994) suggested that the saliency of items controls their stability and the amount of RB.

An alternative perceptual account of RB is the type refractoriness hypothesis (Kanwisher, 1987; Luo \& Caramazza, 1996). According to this view, RB effects are attributed to a property of the activation function of type nodes in long-term memory. After a type node is processed, it has a refractory period. RB may occur if an attempt is made to reactivate a type node during its refractory stage. In the present study, it might be the case that type nodes are in fact different for translation equivalents in two languages. In this case, one would not expect to find RB. However, given that repetition priming effects were found, one can argue that the type nodes are not totally distinct, but that they overlap in terms of semantic features. Moreover, the overlap is greater than that for semantically related words in the same language, given that priming effects were not found for items such as center and middle in previous RB studies using RSVP (see, e.g., Kanwisher \& Potter, 1990). Thus, while this explanation relies on the distinction between type nodes and the temporal lag in encoding $\mathrm{R} 1$ and $\mathrm{R} 2$, it is not totally inconsistent with Kanwisher's token individuation view.

\section{Implications for Bilingual Memory}

The findings of Experiment 2 extend the current literature on repetition effects across languages and provide evidence of facilitation for translations in a serial recall task. While the bulk of the bilingual literature on recall of mixed-language lists includes investigations of performance on free recall (see Keatley, 1992, for a review), there have been no systematic investigations of serial recall for bilingual speakers. The results reported here suggest that, for fluent bilinguals, lexical and conceptual access for translations is rapid, and, even at presentation rates of $125 \mathrm{msec}$ per word in mixed-language lists, mem- ory is increased. The use of mixed-language lists in which all of the conditions were intermixed was meant to reduce any expectancy bias that might have been present through the use of a blocked design (Park \& Kanwisher, 1994). Thus, the present results argue for a model of bilingual memory in which activation of both lexical and conceptual features of words in two languages by a fluent bilingual occurs automatically (e.g., Kroll \& Stewart, 1994).

Cross-language repetition priming effects have also been reported in the literature using lexical decision tasks (e.g., Kirsner et al., 1984). Priming effects have been reported for translation equivalents. However, in general, the magnitude of the priming effect is greater within languages than between languages. In sum, the results reported here indicate that repetition effects can occur for translations in RSVP under the same conditions that produce blindness within languages, suggesting that the existence of distinct visual and language codes allows for the instantiation of two separate tokens for translations.

\section{Conclusions}

The present results support the findings of Kanwisher and Potter (1990) and others and suggest that repetition blindness does not occur solely at a conceptual level. RB can occur for any pair of words that is orthographically or phonologically identical and, in some cases, when there is a partial overlap of features at these levels of representation. With regard to bilingual memory, these data add to our knowledge of language representation and processing for bilinguals by demonstrating that conceptual access in two languages and repetition priming can occur at fast presentation rates.

\section{REFERENCES}

AltaRRIBA, J. (1992). The representation of translation equivalents in bilingual memory. In R. J. Harris (Ed.), Cognitive processing in bilinguals (pp. 157-174). Amsterdam: Elsevier.

BAVELIER, D. (1994). Repetition blindness between visually different items: The case of pictures and words. Cognition, 51, 199-236.

Bavelier, D., \& PotTer, M. C. (1992). Visual and phonological codes in repetition blindness. Journal of Experimental Psychology: Human Perception \& Performance, 18, 134-147.

Bavelier, D., Prasada, S., \& Segui, J. (1994). Repetition blindness between words: Nature of the orthographic and phonological representations involved. Journal of Experimental Psychology: Learning, Memory, \& Cognition, 20, 1437-1455.

BJork, E. L., \& MURRAY, J. T. (1977). On the nature of input channels in visual processing. Psychological Review, 84, 472-484.

BLAXTON, T. A. (1989). Investigating dissociations among memory measures: Support for a transfer-appropriate processing framework. Journal of Experimental Psychology: Learning. Memory; \& Cognition, 15, 657-668.

CHEN, H.-C., \& NG, M.-L. (1989). Semantic facilitation and translation priming effects in Chinese-English bilinguals. Memory \& Cognition, 17, 454-462.

DalRymple-Alford, E. C. (1982). Associations of bilinguals to synonyms and translation-equivalent words. Current Psychological Research, 2, 181-186.

DANNENBRING, G. L., \& BRIAND, K. (1982). Semantic priming and the word repetition effect in a lexical decision task. Canadian Journal of Psychology, 36, 435-444. 
DE Groot, A. M. B. (1984). Primed lexical decision: Combined effects of the proportion of related prime-target pairs and the stimulusonset asynchrony of prime and target. Quarterly Journal of Experimental Psychology, 36A, 253-280.

DE GRoOT, A. M. B. (1993). Word type effects in bilingual processing tasks: Support for a mixed-representational system. In R. Schreuder \& B. Weltens (Eds.), The bilingual lexicon (pp. 27-51). Philadelphia, PA: John Benjamins.

DE GROOT, A. M. B., \& NAS, G. L. J. (1991). Lexical representation of cognates and noncognates in compound bilinguals. Journal of Memory \& Language, 30, 90-123.

Fagot, C., \& PASHLER, H. (1995). Repetition blindness: Perception or memory failure? Journal of Experimental Psychology: Human Perception \& Performance, 21, 275-292.

Frenck, C., \& Pynte, J. (1987). Semantic representation and surface forms: A look at across-language priming in bilinguals. Journal of Psycholinguistic Research, 16, 383-396.

GLanzer, M., \& DuarTe, A. (1971). Repetition between and within languages in free recall. Journal of Verbal Learning \& Verbal Behavior, 10, 625-630.

Hochhaus, L., \& Marohn, K. M. (1991). Repetition blindness depends on perceptual capture and token individuation failure. Journal of Experimental Psychology: Human Perception \& Performance, 17 $422-432$.

Humphreys, G. W., Besner, D., \& Quinlan, P. T. (1988). Event perception and the word repetition effect. Journal of Experimental Psychologv: General, 117, 51-67.

$J_{I N}$, Y. S. (1990). Effects of concreteness on cross-language priming in lexical decision. Perceptual \& Motor Skills, 70, 1139-1154.

KANWISHER, N. (1986). Repetition blindness: Type recognition without token individuation. Unpublished doctoral dissertation, Massachusetts Institute of Technology.

KANWISHER, N. (1987). Repetition blindness: Type recognition without token individuation. Cognition, 27, 117-143.

KANWISHER, N. (1991). Repetition blindness and illusory conjunctions Errors in binding visual types with visual tokens. Journal of Experimental Psvchology: Human Perception \& Performance, 17, 404-421.

Kanwisher, N., \& PotTer, M. C. (1989). Repetition blindness: The effects of stimulus modality and spatial displacement. Memory \& Cognition, 17, 117-124

Kanwisher, N., \& Potter, M. C. (1990). Repetition blindness: Levels of processing. Journal of Experimental Psychology: Human Perception \& Performance, 16, 30-47.

KEATLEY, C. (1992). History of bilingualism research in cognitive psychology. In R. J. Harris (Ed.), Cognitive processing in bilinguals (pp. 15-49). Amsterdam: Elsevier.

Keatley, C., \& DE Gelder, B. (1992). The bilingual primed lexical decision task: Cross-language priming disappears with speeded responses. European Journal of Cognitive Psychology, 4, 273-292.

KirSner, K., SMith, M. C., Lockhart, R. L. S., King, M. L., \& JAIN, M. (1984). The bilingual lexicon: Language-specific units in an integrated network. Journal of Verbal Learning \& Verbal Behavior, 23, 519-539.

KOLERS, P. A. (1966). Interlingual facilitation of short-term memory. Journal of Verbal Learning \& Verbal Behavior, 5, 314-319.

Kolers, P. A., \& Gonzalez, E. (1980). Memory for words, synonyms and translations. Journal of Experimental Psychology: Human Learning \& Memory, 6, 53-65.

KROLL, J. F., \& STEWART, E. (1994). Category interference in translation and picture naming: Evidence for asymmetric connections between bilingual memory representations. Journal of Memory \& Language, 33, 149-174.

KuČERA, H., \& FranCis, W. N. (1967). Computational analysis of present-day American English. Providence, RI: Brown University Press.

Lambert, W. E., Ignatow, M., \& Krauthamer, M. (1968). Bilingual organization in free recall. Journal of Verbal Learning \& Verbal Be havior, 7, 207-214.

LiePMANN, D., \& SAEgerT, J. (1974). Language tagging in bilingual free recall. Journal of Experimental Psychology, 103, 1137-1141.

Luo, C. R., \& CaramazzA, A. (1995). Repetition blindness under minimum memory load: Effects of spatial and temporal proximity and the encoding effectiveness of the first item. Perception \& Psychophysics, 57, 1053-1064.

Luo, C. R., \& Caramazza, A. (1996). Temporal and spatial repetition blindness: Effects of presentation mode and repetition lag on the perception of repeated items. Journal of Experimental Psychology: Human Perception \& Performance, 22, 95-113.

MaCKAY, D. G., \& MilLeR, M. D. (1992). Semantic blindness: Repetition suppression at the semantic level. Unpublished manuscript, University of California, Los Angeles.

MaCKAy, D. G., \& Miller, M. D. (1994). Semantic blindness: Repeated concepts are difficult to encode and recall under time pressure. Psychological Science, 5, 52-55.

MACNAMARA, J., \& KUSHNIR, S. L. (1971). Linguistic independence of bilinguals: The input switch. Journal of Verbal Learning \& Verbal Behavior, 10, 480-487.

Mandler, G., Graf, P., \& Kraft, D. (1986). Activation and elaboration effects in recognition and word priming. Quarterly Journal of Experimental Psychology, 38A, 645-662.

Marohn, K. M., \& Hochhaus, L. (1988). Different-case repetition still leads to perceptual blindness. Bulletin of the Psychonomic Society, 26, 29-31

Miller, M. D., \& MaCKay, D. G. (1994). Repetition deafness: Repeated words in computer-compressed speech are difficult to encode and recall. Psychological Science, 5, 47-51.

Mozer, M. C. (1989). Types and tokens in visual letter perception. Journal of Experimental Psychology: Human Perception \& Performance, 15, 287-303

NAPPS, S. E. (1989). Morphemic relationships in the lexicon: Are they distinct from semantic and formal relationships? Memory \& Cognition, 17, 729-739.

NeEly, J. H., Keefe, D. E., \& Ross, K. L. (1989), Semantic priming in the lexical decision task: Roles of prospective prime-generated expectancies and retrospective semantic matching. Journal of Experimental Psychology: Learning, Memory, \& Cognition, 15, 1003-1019.

NotT, C. R. \& LAMBERT, W. E. (1968). Free recall of bilinguals. Journal of Verbal Learning \& Verbal Behavior, 7, 1065-1071

Paivio, A., Clark, J. M., \& Lambert, W. E. (1988). Bilingual dualcoding theory and semantic repetition effects on recall. Journal of Experimental Psychology: Learning, Memory, \& Cognition, 14, 163-172.

Park, J., \& Kanwisher, N. (1994). Determinants of repetition blindness. Journal of Experimental Psychology: Human Perception \& Performance, 20, 500-519.

Roediger, H. L., III, \& Challis, B. H. (1992). Effects of exact repetition and conceptual repetition on free recall and primed word-fragment completion. Journal of Experimental Psychology: Learning, Memory, \& Cognition, 18, 3-14.

Roediger, H. L., III, SRinivas, K., \& Weldon, M. S. (1989). Dissociations between implicit measures of retention. In S. Lewandowsky, J. C. Dunn, \& K. Kirsner (Eds.), Implicit memory: Theoretical issues (pp. 67-84). Hillsdale, NJ: Erlbaum.

Roediger, H. L., III, Weldon, M. S., \& Challis, B. H. (1989). Explaining dissociations between implicit and explicit measures of retention: A processing account. In H. L. Roediger III \& F. I. M. Craik (Eds.), Varieties of memory and consciousness: Essays in honour of Endel Tulving (pp. 3-14). Hillsdale, NJ: Erlbaum.

Rose, R. G., \& CARRolL, J. F. (1974). Free recall of a mixed language list. Bulletin of the Psychonomic Society, 3, 267-268.

SChWANENFlugel, P. J., \& Rey, M. (1986). Interlingual semantic facilitation: Evidence for a common representational system in the bilingual lexicon. Journal of Memory \& Language, 25, 605-618.

Smith, C. C., Davies, G. A., \& Hall, H. B. (1989). Langenscheidt's compact Spanish dictionary. New York: Langenscheidt.

Tulving, E., \& Colotla, U. (1970). Free recall of trilingual lists. Cognitive Psychology, 1, 86-98.

Tzelgov, J., \& Eben-Ezra, S. (1992). Components of the betweenlanguage semantic priming effect. European Journal of Cognitive Psychology, 4, 253-272.

WELDON, M. S. (1991). Mechanisms underlying priming on perceptual tests. Journal of Experimental Psychology: Learning, Memorv, and Cognition, 17, 526-541.

Whitrlese., B. W. A., Dorken, M. D. \& Podrouzek, K. W. (1995). Repeated events in rapid lists: Part 1 . Encoding and representation. 
Journal of Experimental Psychology: Learning, Memory, \& Cognition, 21, 1670-1688.

WOLFORD, G., \& HOLLingsworTh, S. (1974). Redundancy in the fullreport procedure. Bulletin of the Psychonomic Society, 3, 457-458.

Yin, C., Wojciulik, E., \& Kanwisher, N. (1993, May). Codes mediating repetition blindness for pictures: Phonological, visual or conceptual? Poster presented at the 3rd Annual West Coast Attention Conference, Eugene, OR.

\section{NOTES}

1. However, in Kanwisher and Potter (1990, Experiments 4A and $4 B$ ), RB was not reported when words were phonologically identical but spelled differently as in ate-eight. Bavelier and Potter (1992) suggested that one of the reasons for the difference in the results was that they included a greater number of participants and items than did the previous study. Thus, it appears that the overlap of phonological codes is sufficient to produce RB in sentences as well as in short word lists.

2. One other situation for which blindness does not occur is between morphologically related items with slightly different spellings (e.g., break and broke; Bavelier et al., 1994, Experiment 3). This is surprising given the fact that RB has been demonstrated for orthographic neighbors that share the same degree of overlap as the morphologically related items used in their study. Bavelier et al. noted that in order for RB to occur between orthographically related words that are phonologically distinct, the two words need to share at least three to five letters in the same position.

3. We were successful in 15 out of 18 cases. However, certain exceptions were made to allow for accurate translations for use in Experiment $1 \mathrm{~B}$.

4. We thank Chun Luo for pointing out this possibility.

5. Although Park and Kanwisher (1994, Experiment 5) have suggested that RB may not interact with total memory load, their experiments were conducted using letter lists in a single language.

6. Kanwisher (1987) also reported a repetition benefit on threshold recognition in her third experiment. To account for this effect, she noted, "whether R1 and R2 are individuated as separate events or not, the activation from both stimuli should be summed in the type node. This would increase the activation of the type node, boosting recognition" (p. 135).

\section{APPENDIX A \\ Stimulus Materials Used in Experiment 1A}

1. I thought we had killed the ants (insects) but there were ants in the kitchen.

2. Mike learned to drive (steer) and started to drive to work.

3. We rented this truck (car) and another truck for the trip.

4. Of all my friends (buddies) two good friends are living in Europe.

5. They arrived early for the play (show) though the play had been canceled.

6. Peter told a joke (story) like the joke he had heard yesterday.

7. Samuel sold his books (records) and bought two books with the money.

8. I like steak (meat) but this steak tastes awful.

9. John wanted an apple (a fruit) but the apple was rotten.

10. She needed more clothes (money) to replace the clothes that were lost.

11. To use a recorder (microphone) the recorder needs batteries.

12. Charles was bored (tired) of her and bored in general with everything.

13. We lay in the sun (yard) but the sun disappeared in the clouds.

14. Maggie bought those shoes (stockings) thinking that the shoes would match.

15. Mark is not my son (nephew) but the son of a friend.

16. The circus that had that bear (act) reported that the bear was missing.

17. She ate salad and fish (seafood) even though the fish was raw.

18. Her dress was red (pink) because red is flashy.

\section{APPENDIX B}

Stimulus Materials Used in Experiment $1 B$

1. a. I thought we had killed the ants (insects) pero habian hormigas en la cocina.

b. Yo pensé que habiamos matado las hormigas (los insectos) but there were ants in the kitchen.

2. a. Mike learned to drive (steer) and empesó a manejar al trabajo.

b. Mike aprendió a manejar (guiar) y started to drive to work.

3. a. We rented this truck (car) and otro camión para el viaje.

b. Nosotros rentamos éste camión (carro) y another truck for the trip.

4. a. Of all my friends (buddies) dos buenos amigos estan viviendo en Europa.

b. De todos mis amigos (compañeros) two good friends are living in Europe.

5. a. They arrived early for the play (show) aunque la obra había sido cancelada.

b. Ellos llegaron temprano para la obra (el acto) though the play had been canceled.

6. a. Peter told a joke (story) parecido al chiste que habia oído ayer.

b. Pedro hizo un chiste (cuento) like the joke he had heard yesterday.

7. a. Samuel sold his books (records) and compró dos libros con el dinero.

b. Samuel vendió sus libros (discos) y bought two books with the money.

8. a. I like steak (meat) pero éste bistec sabe mal.

b. Me gusta bistec (carne) but this steak tastes awful.

9. a. John wanted an apple (a fruit) pero la manzana estaba podrida.

b. Juan quería una manzana (fruta) but the apple was rotten.

10. a. She needed more clothes (money) to reemplazar la ropa que se perdió.

b. Ella necesitaba más ropa (dinero) para replace the clothes that were lost. 


\section{APPENDIX B (Continued)}

11. a. To use a recorder (microphone) la grabadora necesita baterías.

b. Para usar una grabadora (un micrófono) the recorder needs batteries

12. a. Charles was bored (tired) with ella y aburrido en general con todo.

b. Carlos estaba aburrido (cansado) con her and bored in general with everything.

13. a. We lay in the sun (yard) pero el sol desapareció en las nubes.

b. Nos acostamos en el sol (patio) but the sun disappeared in the clouds.

14. a. Maggie bought those shoes (stockings) thinking que los zapatos le pegarian.

b. Maggie compró esos zapatos (esas medias) pensando that the shoes would match.

15. a. Mark is not my son (nephew) pero es hijo de un amigo.

b. Marco no es mi hijo (sobrino) but the son of a friend.

16. a. The circus that had that bear (act) reported que el oso estaba perdido.

b. El circo que tenía ese oso (acto) reporto that the bear was missing.

17. a. She ate salad and fish (seafood) aunque el pescado estaba crudo.

b. Ella comió ensalada y pescado (maríscos) even though the fish was raw.

18. a. Her dress was red (pink) porque rojo es llamativo.

b. Su vestido era rojo (rosado) because red is flashy.

Note- $a=$ English-Spanish condition. $b=$ Spanish-English condition.

APPENDIX C

Stimulus Materials Used in Experiment 2

\begin{tabular}{|c|c|c|c|c|c|}
\hline & English & Spanish & & English & Spanish \\
\hline 1. & nephew & sobrino & 37. & door & puerta \\
\hline 2. & drive & manejar & 38. & glue & goma \\
\hline 3. & brush & cepillo & 39. & grass & hierba \\
\hline 4. & bed & cama & 40. & bored & aburrido \\
\hline 5. & pink & rosado & 41. & sky & cielo \\
\hline 6. & couple & pareja & 42. & joke & chiste \\
\hline 7. & thread & hilo & 43. & war & guerra \\
\hline 8. & apple & manzana & 44. & truck & camión \\
\hline 9. & ear & oreja & 45. & cold & frio \\
\hline 10 & son & hijo & 46. & dish & plato \\
\hline 11. & king & rey & 47. & leaf & hoja \\
\hline 12. & hammer & martillo & 48. & queen & reina \\
\hline 13. & finger & dedo & 49. & silver & plata \\
\hline 14. & ants & hormigas & 50. & recorder & grabadora \\
\hline 15. & shoes & zapatos & 51. & fork & tenedor \\
\hline 16. & $\operatorname{man}$ & hombre & 52. & life & vida \\
\hline 17. & tie & corbata & 53. & play & obra \\
\hline 18. & boy & niño & 54. & fish & pescado \\
\hline 19. & socks & medias & 55. & mouth & boca \\
\hline 20. & tired & cansado & 56. & slow & lento \\
\hline 21. & soap & jabón & 57. & clock & reloj \\
\hline 22. & orange & naranja & 58. & shirt & camisa \\
\hline 23. & steak & bistec & 59. & clouds & nubes \\
\hline 24. & plane & avión & 60. & half & mitad \\
\hline 25. & eye & ojo & 61. & water & agua \\
\hline 26. & sour & agrio & 62. & key & llave \\
\hline 27. & sun & sol & 63. & bear & oso \\
\hline 28. & bull & toro & 64. & road & camino \\
\hline 29. & thief & ladrón & 65. & friends & amigos \\
\hline 30. & mouse & ratón & 66. & milk & leche \\
\hline 31. & spoon & cuchara & 67. & rain & lluvia \\
\hline 32. & candle & vela & 68. & arm & brazo \\
\hline 33. & cat & gato & 69. & clothes & ropa \\
\hline 34. & red & rojo & 70. & onion & cebolla \\
\hline 35. & books & libros & 71. & neighbor & vecino \\
\hline 36. & meat & carne & 72. & stick & palo \\
\hline
\end{tabular}

